Abstract

\title{
Cyclodextrine Based Nanogels and Phase Solubility Studies of Flurbiprofen as a Chemopreventive Agent ${ }^{\dagger}$
}

\author{
Ayşe Nur Oktay, Sibel İlbasmiş Tamer and Nevin Çelebi * \\ Department of Pharmaceutical Technology, Faculty of Pharmacy, Gazi University, Etiler 06330, Ankara, \\ Turkey; aysenur.oktay@gazi.edu.tr (A.N.O.); ilbasmis@gazi.edu.tr (S.İ.T.) \\ * Correspondence: ncelebi@gazi.edu.tr; Tel.: +90-312-202-3049 \\ + Presented at the 2nd International Conference on Natural Products for Cancer Prevention and Therapy, \\ Kayseri, Turkey, 8-11 November 2017.
}

Published: 15 November 2017

\begin{abstract}
Flurbiprofen (FB) is one of the nonsteroidal anti-inflammatory drugs (NSAIDs) which has low water solubility (1). In recent studies it is shown that NSAIDs tend to demonstrate chemopreventive activity and chemoprotective agents frequently show low water solubility (2). In this study FB was selected as a model drug. Cyclodextrins (CDs) which are natural products and have special structure (hydrophobic inner phase and hydrophilic outer phase), have been widely used to enhance solubility and stability of drug substances (3). The objective of this study was to prepare $\mathrm{CD}$ based nanogels for increasing solubility and stability of FB. Nanogels were prepared with two different ratio $(0.02$ and $20 \%)$ and type of $C D(\beta C D$ and $\mathrm{HP} \beta C D)$ using emulsificationsolvent evaporation technique. Particle size (PS), polydispersity index (PDI), zeta potential (ZP) were investigated and phase solubility studies were performed to optimize CD based nanogels. According to results of phase solubility studies; it was achieved to enhance water solubility of FB with HPßCD 56.7 fold. PS, PDI and ZP were found as $154.5 \pm 3.1 \mathrm{~nm}, 0.25 \pm 0.01,-60 \pm 2 \mathrm{mV}$ for $0.02 \% \mathrm{HP} \beta \mathrm{CD}$ and $270.7 \pm 58.2 \mathrm{~nm}, 0.52 \pm 0.06,-28.9 \pm 2.3 \mathrm{mV}$ for $20 \% \mathrm{HP} \beta \mathrm{CD}$ respectively. It can be concluded that $\mathrm{HP} \beta \mathrm{CD}$ based nanogels can be promising carriers for $\mathrm{FB}$ as a chemopreventive agent.
\end{abstract}

Keywords: chemopreventive; flurbiprofen; cyclodextrin; solubility; nanogel

Conflicts of Interest: The authors declare no conflict of interest.

(C) 2017 by the authors. Licensee MDPI, Basel, Switzerland. This article is an open access article distributed under the terms and conditions of the Creative Commons Attribution (CC BY) license (http://creativecommons.org/licenses/by/4.0/). 